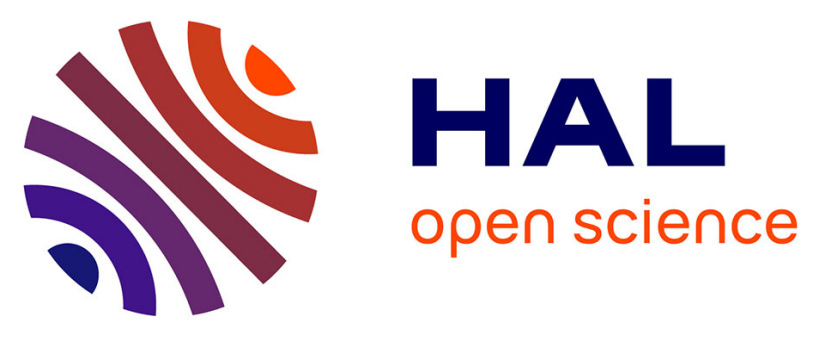

\title{
Do adolescents accurately evaluate their diet quality? The HELENA study
}

\author{
Jeremy Vanhelst, Laurent Beghin, Alain Duhamel, Stefaan de Henauw, \\ Jonatan R Ruiz, Anthony Kafatos, Odysseas Androutsos, Kurt Widhalm, \\ Beatrice Mauro, Michael Sjostrom, et al.
}

\section{To cite this version:}

Jeremy Vanhelst, Laurent Beghin, Alain Duhamel, Stefaan de Henauw, Jonatan R Ruiz, et al.. Do adolescents accurately evaluate their diet quality? The HELENA study. Clinical Nutrition, 2017, 36 (6), pp.1669-1673. 10.1016/j.clnu.2016.10.019 . hal-02176971

\section{HAL Id: hal-02176971 \\ https://hal.univ-lille.fr/hal-02176971}

Submitted on 8 Jul 2019

HAL is a multi-disciplinary open access archive for the deposit and dissemination of scientific research documents, whether they are published or not. The documents may come from teaching and research institutions in France or abroad, or from public or private research centers.
L'archive ouverte pluridisciplinaire HAL, est destinée au dépôt et à la diffusion de documents scientifiques de niveau recherche, publiés ou non, émanant des établissements d'enseignement et de recherche français ou étrangers, des laboratoires publics ou privés. 
1 Article title: Do adolescents accurately evaluate their diet quality? The HELENA study

2 Short running head: adolescents' dietary awareness

3
Jérémy Vanhelst ${ }^{1}$, Laurent Béghin ${ }^{1}$, Alain Duhamel ${ }^{2}$, Stefaan De Henauw ${ }^{3}$, Jonatan R

Ruiz $^{4}$, Anthony Kafatos ${ }^{5}$, Odysseas Androutsos ${ }^{6}$, Kurt Widhalm ${ }^{7}$, Beatrice Mauro ${ }^{8}$, Michael Sjöström ${ }^{9}$, Mathilde Kersting ${ }^{10}$, Frédéric Gottrand ${ }^{1}$

${ }^{1}$ Univ. Lille, Inserm, CHU Lille, U995 - LIRIC - Lille Inflammation Research International Center, CIC 1403 - Centre d'investigation clinique, F-59000 Lille, France

${ }^{2}$ Univ. Lille, CHU Lille, EA 2694 - Santé publique : épidémiologie et qualité des soins, F59000 Lille, France

${ }^{3}$ Department of Movement and Sport Sciences, Ghent University, Ghent, Belgium

${ }^{4}$ PROFITH "PROmoting FITness and Health through physical activity" Research Group, Department of Physical Educationand Sport, Faculty of Sport Sciences, University of Granada, Granada, Spain

5 University of Crete School of Medicine,Department of Social Medicine, Preventive Medicine and Nutrition Clinic,Heraclion,Crete, Greece

${ }^{6}$ Department of Nutrition and Dietetics, Harokopio University, Athens, Greece

${ }^{7}$ Private Medical University Salzburg, Dept. of Pediatrics, Austria

${ }^{8}$ Agricultural Research Council - Research Center on Food and Nutrition - C.R.A. NUT (formerly INRAN), Roma, Italy

${ }^{9}$ Unit for Preventive Nutrition, Department of Biosciences and Nutrition, Karolinska Institutet, Huddinge, Sweden 
$23{ }^{10}$ Forschungsinstitut fur Kindererna hrung, Institut ander Rheinischen Friedrich-Wilhelms24 Universitat Bonn, Dortmund, Germany

25 5 41

\section{Corresponding author information: J. Vanhelst}

Antenne pédiatrique du CIC

Hôpital Jeanne de Flandre

CHRU de Lille

Avenue Eugène Avinée

59037 Lille Cedex

Tel: +33 320446058

Fax: +33 320446687

E-mail: jeremy.vanhelst@chru-lille.fr

Abbreviations: Healthy Lifestyle in Europe by Nutrition in Adolescence (HELENA), Diet Quality Index for Adolescent (DQI-A), HELENA Dietary Intake Assessment Tool (HELENA-DIAT), Healthy Lifestyle in Europe by Nutrition in Adolescence (HELENA), 9 Flemish food-based dietary guidelines (FBDGs), Body mass index (BMI), International Standard Classification of Education (ISCED). 
41

42

43

44

45

46

47

\section{SUMMARY}

Background and aims: The aim of this study was to assess the diet quality awareness and associated factors in a large sample of European adolescents.

Methods: The study included 3389 healthy adolescents, aged 12.5-17.5 years, who participated in the Healthy Lifestyle in Europe by Nutrition in Adolescence (HELENA) Study. The adolescents' diet quality was based on repeated $24 \mathrm{~h}$ recalls and scored into a Diet Quality Index for Adolescents (DQI-A) considering four components: meal, equilibrium, diversity and quality. A self-rated diet quality questionnaire was administered to adolescents to assess their dietary awareness. The association of DQI-A with dietary awareness was studied using a linear mixed model including the center as the random effect and dietary awareness as the fixed effect.

Results: There was a positive association between DQI-A scores and diet quality perception levels $(p<0.0001)$. The mean DQI-A was $59.0(\mathrm{SD}=14.8)$ in adolescents with a low dietary awareness compared with $65.4(\mathrm{SD}=12.6)$ in adolescents with high dietary awareness $(p<$ 0.0001). Similar results were found for all the DQI components. When analyses were stratified, we found a significant heterogeneity across the nutritional status, with no significant association between DQI-A and dietary awareness level in obese adolescents, but a positive association in overweight, normal and undernourished groups. We found also a significant heterogeneity associated with the lunch location (school or home). No other factor affected dietary awareness (gender, pubertal status and maternal educational level).

Conclusion: European adolescents evaluate well their food quality whatever their pubertal status, gender and parental educational level, except for the obese who are not able to assess their diet quality. Improving the dietary awareness in obese adolescents might help to induce behavioral changes.

Keywords: Youth; Assessment; Nutrition; Awareness; Epidemiology study 
66

\section{Introduction}

The prevalence of obesity has tripled in European countries in the last 30 years, and continues to rise at an alarming rate, especially in young people [1]. Overweight and obesity have many health consequences, making prevention particularly important [2]. In children, dietary habits are closely related to overweight and obesity [3-4].

Adolescence represents a period during which multiple physiological and psychological changes occur that considerably affect dietary habits [5-6]. The rapid physical growth that occurs during this period is associated with an increase in nutritional needs. Adolescence is marked by an increasing intake of energy-dense foods that are low in nutrients such as snacks and sugar-sweetened beverages and a decrease in intake of nutrient-dense foods such as fruits and vegetables [7-9]. Intervention or promotion programs for a healthy diet have been shown to have limited success in childhood and adolescence [10-11]. Lack of awareness of personal dietary habits has been identified as a major barrier to motivating adults to change to healthier diets [12]. We hypothesized that a similar barrier would apply for adolescents. Indeed, adolescents may think that they achieve healthy dietary habits because they wrongly assess their diet quality.

Therefore, the aim of the present study was to examine the diet quality awareness in a large sample of European adolescents. A secondary aim was to investigate factors associated with diet quality awareness.

\section{Methods}

\subsection{Study design}

The Healthy Lifestyle in Europe by Nutrition in Adolescence Cross-Sectional Study (HELENA-CSS) is a multicenter study performed in 10 European cities belonging to nine 
countries. The HELENA-CSS was designed to obtain reliable and comparable data on nutrition and health-related parameters from a sample of European adolescents aged 12.5 17.5 yr. A sample of 3,528 adolescents met the HELENA general inclusion criteria. A detailed description of the HELENA study's methodology and sampling has been published elsewhere [13-15].

Written, informed consent was obtained from the adolescent and the parents. The HELENA study was approved by the local ethics committee in each country, and all procedures were performed in accordance with the ethical standards of the Helsinki Declaration of 1975 as revised in 2008 and the European Good Clinical Practices [16].

\subsection{Measurements}

\subsubsection{Self-rated diet quality}

Self-rated diet quality was assessed using a questionnaire. The adolescent was asked the single question: "Your diet is: rather unhealthy, not healthy or unhealthy, rather healthy, healthy, very healthy". A healthy eating was defined as "a healthy diet is a well-balanced diet which contains a lot of fruit, vegetables and dairy products, a good portion of starchy foods like bread, potatoes and pasta, a moderate portion of meat or fish, and not too much fat and sugar. Also the intake of a large amount of fluid is very important in a healthy diet. The energy content of a healthy diet is in accordance with the needs of the human body" [17]. For the assessment of diet quality, the answers were classified a priori into three categories: low when the answer was "rather unhealthy" or "not healthy or unhealthy", medium when the answer was "rather healthy" and high when the answer was "healthy" or "very healthy". This question about awareness was extracted from a healthy diet determinants questionnaire that has been previously found to be reliable and valid, specifically awareness question correlated well with fresh fruit, soft drinks and ascorbic acid [18]. 


\subsubsection{Diet quality assessment}

Dietary intake was assessed by two nonconsecutive 24-hour recalls performed on any two convenient days of the week [19]. The 24-hour recalls were recorded using a selfadministered, computer-based HELENA Dietary Intake Assessment Tool (HELENA-DIAT) that has been validated in European adolescents [20]. Detailed descriptions of data collection and analysis have been published elsewhere [20-24].

\subsubsection{Participants' characteristics}

Weight was measured in light clothes, without shoes, to the nearest $0.1 \mathrm{~kg}$ using an electronic scale (SECA 871; SECA, Hamburg, Germany). Height was measured without shoes to the nearest $0.1 \mathrm{~cm}$ using a telescopic height-measuring instrument (SECA 225; SECA). Body mass index (BMI) was calculated as weight $(\mathrm{kg}) / \mathrm{height}^{2}\left(\mathrm{~m}^{2}\right)$. Nutritional status was assessed according to the International Obesity Task Force scale [25]. Pubertal status was assessed by a physician through direct observation according to Tanner and Whitehouse [26]. Maternal educational level was classified into one of four categories using a specific questionnaire adapted from the International Standard Classification of Education (ISCED) (http://www.uis.unesco.org/ Library/Documents/isced97-en.pdf), and was scored as 1: primary and lower education (levels 0,1 and 2 in the ISCED classification); 2: higher secondary (levels 3 and 4 in the ISCED classification); and 3: tertiary (levels 5 and 6 in the ISCED classification).

\subsection{Statistical analysis}

Data are presented as percentages for qualitative variables and mean \pm standard deviation (SD) for quantitative variables. Normality of distribution was checked graphically and using the Shapiro-Wilk test. 
To assess the selection bias related to missing or incomplete data, the main characteristics of the included and nonincluded adolescents were compared using a Student $t$ test for quantitative variables, a chi-square test for categorical variables and the MantelHaenszel trend test for qualitative ordinal variables.

The association of DQI-A with dietary awareness was studied using a linear mixed model including the center as a random effect and diet quality perception level as the fixed

142 effect (treated as an ordinal factor). We performed key subgroup analyses based on gender, 143 pubertal status, nutritional status, maternal educational level and place adolescents used to

144 have lunch (school or home). Heterogeneity in the association of DQI-A with dietary 145 awareness level across subgroups was assessed by adding a multiplicative term into the linear 146 mixed model.

All statistical tests were performed at a 2-tailed $\alpha$ level of 0.05 . Data were analyzed using SAS version 9.4 [SAS Institute Inc., Cary, NC 27513, USA].

\section{Results}

Of 3528 adolescents meeting the inclusion criteria, 3389 (96\%) were finally included in the statistical analysis after excluding those with missing or incomplete data for self-rated quality of diet. Characteristics of the population studied are presented in Table 1. Except for maternal educational level, there were no significant differences found between the included and nonincluded groups.

As shown in Figure 1, the DQI-A score increased gradually with the adolescent's 157 dietary awareness level $(p<0.0001)$. The mean DQI-A was $59.0(\mathrm{SD}=14.8)$ in adolescents 158 with a low dietary awareness compared with $65.4(\mathrm{SD}=12.6)$ in adolescents with a high dietary awareness. Similar results were found for all the DQI components. 
When analyses were stratified according to key subgroups, no heterogeneity in the association of DQI-A and dietary awareness level was found for gender, pubertal status or maternal education level (Table 2). We found a significant heterogeneity associated with the

163 lunch location (school or home). The positive association between DQI-A and diet awareness

164 was stronger in adolescents who eat at home than those eating at school (Table 2). In addition, 165 we found also a significant heterogeneity associated with nutritional status, with obese 166 adolescents showing no significant association between DQI-A and dietary awareness, while 167 a positive association was found for the overweight, normal and underweight groups (Table

168 2). The mean difference in DQI-A between the highest and lowest dietary awareness level 169 was 9.3 in the underweight, 6.9 in those of normal weight, 5.2 in the overweight and 0.5 in the 170 obese. Similar results were found for each DQI component (Table 3).

\section{$171 \quad 4 . \quad$ Discussion}

Although several studies have been performed to evaluate the perception of dietary intake in children and adolescents, our study is the first to investigate the relationship between diet quality and the awareness of diet quality in European adolescents [27]. We hypothesized that a lack of awareness of personal dietary habits could be a major barrier for intervention 176 programs aimed at promoting a healthy diet.

Unexpectedly, our main finding was that European adolescents, regardless of gender,

178 pubertal status, maternal educational level and lunch location, correctly assess their own diet 179 quality. While adolescents have been shown to have difficulties in qualifying their daily 180 physical activity (they tend to overestimate their physical activity patterns), our data show that 181 is not the case for their assessment of diet quality [28]. This probably results from education 182 and information about a "healthy" diet in the European countries included in the study. 
183 Gender, pubertal status or educational level did not affect diet quality awareness, whereas these variables were demonstrated to have an influence on physical activity awareness [29]. Another important finding from our study is that obese adolescents do not have a valid perception of their diet quality. In addition to underestimating their weight and energy intake, our results show that obese adolescents do not discriminate well between a healthy or unhealthy diet [28-32]. This is an additional factor that could contribute to the failure of intervention programs that aim to reduce obesity. Our observation that obese adolescents misreport their diet quality emphasizes the importance of improving awareness of diet quality, the first step in any intervention to promote a healthy diet. Based on the results presented in our study, regular feedback to obese adolescents on their dietary quality might be beneficial and could motivate them to adjust their own diet throughout the day. New technology, such as nutrition applications for mobile devices, could be used to give regular and rapid feedback on dietary intake quality, and therefore might improve dietary intake quality perception and behaviors [33-35]. This method presents a great opportunity to modify awareness and might instill healthy behaviors, while providing objective information about individual dietary quality might bring about a more realistic estimation of dietary quality by obese European adolescents. Another possible explanation for the misperception of diet quality by obese adolescents is the influence of social desirability (the tendency to respond so as to avoid criticism) and social approval (the tendency to seek praise), which can bias answers in selfreporting [35].

In our study, we found a stronger positive association between DQI-A and diet awareness in adolescents who eat at home compared to those eating at school. This difference might be due to the influence of the family on healthy diet awareness. However a significant positive between DQI-A and awareness was found both in adolescent eating at home and those eating at school. 
The current study has strengths and limitations. The strengths of the study are the large 209 sample size of adolescents in 10 European cities, the use of standardized procedures, and the

210 strong methodology used to assess dietary habits [36]. The limitations of the study include the

211 cross-sectional design with observed associations, which cannot be interpreted to reflect 212 causal relationships. In addition, even though the HELENA-DIAT has been validated against 213 dietary recall with an interviewer, the main limitation is the subjectivity, especially in obese 214 people, of the assessment of dietary intake that was evaluated only by the adolescent 215 participants. Then, as this study was performed ten years ago (2006-2007), we could not 216 exclude our results represent the present situation.

\section{5. Conclusions}

218 Adolescents evaluate well their food quality independent of their pubertal status, gender 219 and parental educational level, except for obese adolescents who are not able to assess 220 accurately their diet quality. Improving dietary awareness in obese adolescents might help to 221 induce behavioral changes. 
The authors thank the participants for taking part in the study. The HELENA study is made possible by the financial support of the European Community Sixth RTD Framework

225 Programme (Contract FOOD-CT-20056007034) and the Spanish Ministry of Science and 226 Innovation (RYC-2010-05957). The content of this paper reflects only the authors' views, and 227 the European Community is not liable for any use that may be made of the information 228 contained therein.

229

\section{Conflict of interest}

231 The authors do not have any competing interests.

232

\section{Acknowledgements}

234 The authors thank the participants for taking part in the study. 


\section{References}

237 1. NCD-RisC. Trends in adult body-mass index in 200 countries from 1975 to 2014: a pooled 238 analysis of 1698 population-based measurement studies with $19 \cdot 2$ million participants. The 239 Lancet 2016; 387: 1377-1396

2. Procter KL. The aetiology of childhood obesity: A review. Nutr Res Rev 2007; 20: 29-45.

3. Nicklas TA, Yang SJ, Baranowski T, Zakeri I, Berenson G. Eating patterns and obesity in children. The Bogalusa Heart Study. Am J Prev Med 2003; 25: 9-16.

4. Barlow SE. Expert committee recommendations regarding the prevention, assessment, and treatment of child and adolescent overweight and obesity: Summary report. Pediatr 2007; 120: S164-S192.

5. Lake AA, Mathers JC, Rugg-Gunn AJ, Adamson AJ. Longitudinal change in food habits between adolescence (11-12 years) and adulthood (32-33 years): the ASH30 Study. J Public 252 Heatlh 2006; 28: 10-16.

6. Von Post-Skagegård M, Samuelson G, Karlström B, Mohsen R, Berglund L, Bratteby LE. Changes in food habits in healthy Swedish adolescents during the transition from adolescence to adulthood. Eur J Clin Nutr 2002; 56: 532-538.

7. Guenther PM, Dodd KW, Reedy J, Krebs-Smith SM. Most Americans eat much less than recommended amounts of fruits and vegetables. J Am Diet Assoc 2006; 106: 1371-1379. 
261 8. Nielsen S, Siega-Riz A, Popkin B. Trends in energy intake in the U.S. between 1977 and 262 1996: similar shifts seen across age groups. Obes Res 2002; 10: 370-378.

264 9. Wang YC, Bleich SN, Gortmaker SL. Increasing caloric contribution from sugar265 sweetened beverages and 100\% fruit juices among US children and adolescents, 1988-2004. 266 Pediatrics 2008; 121: 1604-1614.

267 10. Luckner H, Moss JR, Gericke CA. Effectiveness of interventions to promote healthy 268 weight in general populations of children and adults: a meta-analysis. Eur J Public Health 269 2012; 22: 491-497.

271 11. Hingle MD, O'Connor TM, Dave JM, Baranowski T. Parental involvement in 272 interventions to improve child dietary intake: a systematic review. Prev Med 2010; 51: 103 273111.

12. Oenema A, Brug J. Feedback strategies to raise awareness of personal dietary intake: results of a randomized controlled trial. Prev Med 2003; 36: 429-439.

13. Béghin L, Huybrechts I, Vicente-Rodríguez G, De Henauw S, Gottrand F, Gonzales279 Gross M, Dallongeville J, Sjöström M, Leclercq C, Dietrich S, et al. Main characteristics and 280 participation rate of European adolescents included in the HELENA study. Arch Public $281 \quad$ Health 2012; 19; 70: 14. 
285 Healthy Lifestyle in Europe by Nutrition in Adolescence Cross-Sectional Study. Int J Obes 286 2008; 32: S4-11.

287

15. Moreno LA, González-Gross M, Kersting M, Molnar D, De Henauw S, Beghin L, 289 Sjöström M, Hagströmer M, Manios Y, Gilbert CC et al. Assessing, understanding and 290 modifying nutritional status, eating habits and physical activity in European adolescents: the 291 HELENA (Healthy Lifestyle in Europe by Nutrition in Adolescence) study. Public Health 292 Nutr 2008; 11: 288-299.

293

16. Béghin L, Castera M, Manios Y, Gilbert CC, Kersting M, De Henauw S, Kafatos A, 295 Gottrand F, Molanr D, Sjöström M et al. Quality assurance of ethical issues and regulatory 296 aspects relating to good clinical practices in the HELENA Cross-Sectional Study. Int J Obes 297 2008; 32: S12-S12.

298

17. Gonzalez-Gross M, De henauw S, Gottrand F, Gilbert C, Moreno L. Manual of operation: 300 The HELENA study, Prensas de la Universidad de Zaragoza: Zaragoza, 2013.

18. Vereecken C, De Henauw S, Maes L, Moreno L, Manios Y, Phillipp K, Plada M, De

303 Bourdeaudhuij I. Reliability and validity of a healthy diet determinants questionnaire for 304 adolescents. Public Health Nutr 2009; 12: 1830-8.

306 19. Biró G, Hulshof KF, Ovesen L, Amorim Cruz JA. Selection of methodology to assess 307 food intake. Eur J Clin Nutr 2002; 56 Suppl 2: S25-32. 
20. Vereecken CA, Covents M, Sichert-Hellert W, Alvira JM, Le Donne C, De Henauw S, De

309 Vriendt T, Phillipp MK, Béghin L, Manios Y et al. Development and evaluation of a self310 administered computerized 24-h dietary recall method for adolescents in Europe. Int J Obes $3112008 ; 32$ Suppl 5, S26-S34.

312

21. Dehne LI, Klemm C, Henseler G, Hermann-Kunz E. The German Food Code and 314 Nutrient Data Base (BLS II.2). Eur J Epidemiol 1999; 15: 355-59.

22. Béghin L, Dauchet L, De Vriendt T, Cuenca-García M, Manios Y, Toti E, Plada M,

Widhalm K, Repasy J, Huybrechts I, et al. Influence of parental socio-economic status on diet quality of European adolescents: results from the HELENA study. Br J Nutr 2013; 13: 1-10.

23. VIG. De actieve voedingsdriehoek: een praktische voedings - en beweeggids (The Active Food Pyramid: A Practical Guide to Diet and Physical Activity). Brussels: Vlaams Instituut voor Gezondheidspromotie (VIG), 2012.

24. Vyncke K, Cruz-Fernandez E, Fajo-Pascual M, Cuenca-Garcia M, De Keyser W,

324 Gonzalez-Gross M, Moreno LA, Béghin L, Breidenassel C, Kersting M et al. Validation of 325 the Diet Quality Index for adolescents by comparison with biomarkers, nutrient and food intakes : the HELENA study. Br J Nutr 2013; 109: 2067-78. overweight and obesity worldwide: international survey. BMJ 2000; 320: 1240-3. 
26. Tanner JM, Whitehouse RH. Clinical longitudinal standards for height, weight, height velocity, weight velocity, and stages of puberty. Arch Dis Child 1976; 51: 170-179.

27. Forrestal SG. Energy intake misreporting among children and adolescents: a literature review. Matern Child Nutr 2011; 7: 112-127.

28. Corder K, van Sluijs EM, Goodyer I, Ridgway CL, Steele RM, Bamber D, Dunn V, Griffin SJ, Ekelund U. Physical activity awareness of British adolescents. Arch Pediatr Adolesc Med 2011; 165: 603-609

29. Béghin L, Huybrechts I, Ortega FB, Coopman S, Manios Y, Wijnhoven TM, Duhamel A, Ciarapica D, Gilbert CC, Kafatos A et al. Nutritional and pubertal status influences accuracy of self-reported weight and height in adolescents: the HELENA Study. Ann Nutr Metab 2013; 62: 189-200.

30. Rangan AM, Flood VM, Gill TP. Misreporting of energy intake in the 2007 Australian Children's Survey: identification, characteristics and impact of misreporters. Nutrients. 2011; 3: 186-199.

31. Maximova K, McGrath JJ, Barnett T, O’Loughlin J, Paradis G, Lambert M. Do you see what I see? Weight status misperception and exposure to obesity among children and adolescents. Int J Obes 2008; 32: 1008-1015.

32. Murakami K, Miyake Y, Sasaki S, Tanaka K, Arakawa M. Characteristics of under- and over-reporters of energy intake among Japanese children and adolescents: The Ryukyus Child Health Study. Nutrition 2012; 28: 532-538. 
355 33. Schap TE, Zhu F, Delp EJ, Boushey CJ. Merging dietary assessment with the adolescent 356 lifestyle. J Hum Nutr Diet 2014; 27: 82-88.

358 34. Lieffers JR, Hanning RM. Dietary assessment and self-monitoring with nutrition 359 applications for mobile devices. Can J Diet Pract Res 2012; 73: e253-60.

361 35. Hebert JR, Ma Y, Clemow L, Ockene IS, Saperia G, Stanek EJ 3rd, Merriam PA, Ockene

362 JK. Gender differences in social desirability and social approval bias in dietary self-report. 363 Am J Epidemiol 1997; 146: 1046-1055.

365 36. Julián-Almárcegui C, Bel-Serrat S, Kersting M, Vicente-Rodriguez G, Nicolas G, Vyncke 366 K, Vereecken C, De Keyzer W, Beghin L, Sette S, et al. Comparison of different approaches 367 to calculate nutrient intakes based upon 24-h recall data derived from a multicenter study in 368 European adolescents. Eur J Nutr 2016 ; 55 : 537-545. 
$371 \quad$ Legends

372 Figure 1. DQI-A according to the adolescents' diet quality awareness.

373 
Table 1. Comparison of mean characteristics between the included and non-included adolescents

\begin{tabular}{|c|c|c|c|}
\hline & Included & Not included & $\mathbf{P}$ \\
\hline Number of adolescents & 3389 & 139 & \\
\hline Gender $(\%$ boys $)$ & 47.4 & 55.4 & 0.06 \\
\hline Age $(y r)$ & $14.7 \pm 1.2$ & $14.7 \pm 1.3$ & 0.69 \\
\hline Nutritional status $(\% U W / \% N W / \% O W / \% O)^{\mathrm{a}}$ & $6.2 / 70.9 / 17.3 / 5.6$ & $3.6 / 67.6 / 22.3 / 6.5$ & 0.09 \\
\hline Pubertal status $(\% I I / \% I I I / \% I V / \% V)^{\mathrm{b}}$ & $6.0 / 22.3 / 42.2 / 29.5$ & $8.0 / 27.0 / 41.0 / 24.0$ & 0.11 \\
\hline Mother education level $(\% I / \% I I / \% I I I)^{\mathrm{c}}$ & 34.7 / 31.4 / 33.9 & $47.1 / 30.0 / 22.9$ & 0.02 \\
\hline Place adolescents used to have lunch (\%school) & 23.8 & 26.1 & 0.68 \\
\hline \multicolumn{4}{|l|}{ For boys } \\
\hline Z-score for height & $0.64 \pm 1.04$ & $0.56 \pm 1.04$ & 0.53 \\
\hline Z-score for weight & $0.68 \pm 0.98$ & $0.80 \pm 0.97$ & 0.29 \\
\hline Z-score for BMI * & $0.40 \pm 1.00$ & $0.60 \pm 1.00$ & 0.08 \\
\hline \multicolumn{4}{|l|}{ For girls } \\
\hline Z-score for height & $0.31 \pm 1.02$ & $0.21 \pm 0.97$ & 0.47 \\
\hline Z-score for weight & $0.45 \pm 0.83$ & $0.43 \pm 0.69$ & 0.86 \\
\hline Z-score for BMI* & $0.34 \pm 0.87$ & $0.35 \pm 0.80$ & 0.94 \\
\hline
\end{tabular}

${ }^{a}$ Nutritional status: underweight (UW), normal weight $(\mathrm{NW})$, overweight $(\mathrm{OW})$, obese $(\mathrm{O})$

${ }^{\mathrm{b}}$ Pubertal status staging according to Tanner

${ }^{\mathrm{c}}$ Education level: lower education (I); higher secondary education (II); higher education or university degree (III).

* Body Mass Index 
Table 2. DQI-A according to the adolescents' diet quality awareness and key subgroups

\begin{tabular}{|c|c|c|c|c|c|}
\hline \multicolumn{6}{|c|}{ Diet quality self-assessment } \\
\hline & Low & Median & High & $\mathbf{P *}$ & P het \\
\hline \multicolumn{6}{|l|}{ Gender } \\
\hline Boys & $56.0(15.6)^{* *}$ & $61.7(13.8)$ & $63.4(13.2)$ & $<0.0001$ & \multirow{2}{*}{0.59} \\
\hline Girls & $61.5(13.6)$ & $63.5(13.2)$ & $67.3(11.7)$ & $<0.0001$ & \\
\hline \multicolumn{6}{|l|}{ Nutritional status } \\
\hline Undernourished & $57.0(12.8)$ & $62.6(13.6)$ & $66.3(12.8)$ & $<0.0001$ & \multirow{4}{*}{0.006} \\
\hline Normal Weight & $58.7(14.9)$ & $62.2(13.3)$ & $65.6(12.3)$ & $<0.0001$ & \\
\hline Overweight & $59.2(15.1)$ & $64.0(14.0)$ & $64.4(13.7)$ & 0.002 & \\
\hline Obese & $62.2(14.3)$ & $67.8(14.7)$ & $62.7(13.9)$ & 0.42 & \\
\hline \multicolumn{6}{|l|}{ Pubertal status } \\
\hline II & $60.0(13.6)$ & $63.3(11.7)$ & $65.4(13.0)$ & 0.016 & \multirow{4}{*}{0.12} \\
\hline III & $58.9(14.9)$ & $64.4(12.9)$ & $65.0(13.1)$ & $<0.0001$ & \\
\hline IV & $58.9(14.7)$ & $61.8(13.8)$ & $64.5(13.1)$ & $<0.0001$ & \\
\hline $\mathrm{V}$ & $58.8(15.4)$ & $62.7(13.8)$ & $67.5(10.9)$ & $<0.0001$ & \\
\hline \multicolumn{6}{|l|}{ Mother education level } \\
\hline I & $55.7(15.3)$ & $59.0(14.3)$ & 59.7 (13.9) & $<0.0001$ & \multirow{3}{*}{0.27} \\
\hline II & $61.3(13.6)$ & $64.0(12.8)$ & $66.5(11.3)$ & $<0.0001$ & \\
\hline III & $62.3(13.4)$ & $65.6(12.1)$ & $68.9(10.6)$ & $<0.0001$ & \\
\hline \multicolumn{6}{|l|}{$\begin{array}{l}\text { Place adolescents } \\
\text { used to have lunch }\end{array}$} \\
\hline School & $61.5(12.4)$ & $64.3(12.3)$ & $66.9(11.6)$ & $<0.0001$ & \multirow{2}{*}{0.043} \\
\hline Home & $58.8(15.3)$ & $62.6(14.0)$ & $66.1(12.6)$ & $<0.0001$ & \\
\hline
\end{tabular}

$\mathrm{P}$ het indicates p-values for heterogeneity in relation to DQI-A and diet awareness level across key subgroups.

* $\mathrm{P}$ for trend adjusted for center using linear mixed effect model (diet perception level was treated as an ordinal factor).

**mean (Standard Deviation) 
Table 3. DQI components according to the adolescents' diet quality awareness and nutritional status

\begin{tabular}{|c|c|c|c|c|}
\hline \multicolumn{5}{|c|}{ Diet awareness } \\
\hline & Low & Median & High & $\mathbf{P *}$ \\
\hline \multicolumn{5}{|l|}{ Underweight } \\
\hline DQI-Quality & $28.0(35.4)$ & $38.6(33.5)$ & $43.4(33.8)$ & 0.013 \\
\hline DQI-Equilibrium & $37.8(9.9)$ & $40.5(11.1)$ & $44.5(12.4)$ & 0.001 \\
\hline DQI-Diversity & $72.0(14.4)$ & $76.6(13.3)$ & $79.4(12.6)$ & $<0.0001$ \\
\hline DQI-Meal & $91.7(12.1)$ & $94.9(12.4)$ & $96.5(8.6)$ & 0.019 \\
\hline \multicolumn{5}{|l|}{ Normal Weight } \\
\hline DQI-Quality & $35.7(38.5)$ & $40.9(34.6)$ & $46.7(32.7)$ & $<0.0001$ \\
\hline DQI-Equilibrium & $38.6(10.0)$ & $40.8(10.4)$ & $43.1(10.2)$ & $<0.0001$ \\
\hline DQI-Diversity & $70.9(14.5)$ & $74.1(14.0)$ & $78.0(13.2)$ & $<0.0001$ \\
\hline DQI-Meal & $90.0(14.8)$ & $93.1(12.3)$ & $94.9(10.9)$ & $<0.0001$ \\
\hline \multicolumn{5}{|l|}{ Overweight } \\
\hline DQI-Quality & $40.2(40.1)$ & $50.1(35.3)$ & $49.3(36.4)$ & 0.004 \\
\hline DQI-Equilibrium & $39.1(10.7)$ & $42.3(10.5)$ & $42.5(11.2)$ & 0.0007 \\
\hline DQI-Diversity & $71.0(14.8)$ & $72.5(14.9)$ & $74.5(15.3)$ & 0.045 \\
\hline DQI-Meal & $87.6(16.0)$ & $91.7(13.5)$ & $91.5(13.9)$ & 0.017 \\
\hline \multicolumn{5}{|l|}{ Obese } \\
\hline DQI-Quality & $48.3(39.5)$ & $54.7(33.4)$ & $51.8(32.6)$ & 0.41 \\
\hline DQI-Equilibrium & $40.0(9.6)$ & $44.6(12.4)$ & $42.3(10.2)$ & 0.11 \\
\hline DQI-Diversity & $70.6(15.2)$ & $75.0(16.9)$ & $71.0(16.0)$ & 0.50 \\
\hline DQI-Meal & $90.2(14.4)$ & $95.4(10.8)$ & $84.5(15.0)$ & 0.23 \\
\hline
\end{tabular}

* $\mathrm{P}$ for trend adjusted for center using linear mixed effect model (diet awareness level was treated as an ordinal factor).

Values are mean (Standard Deviation) 


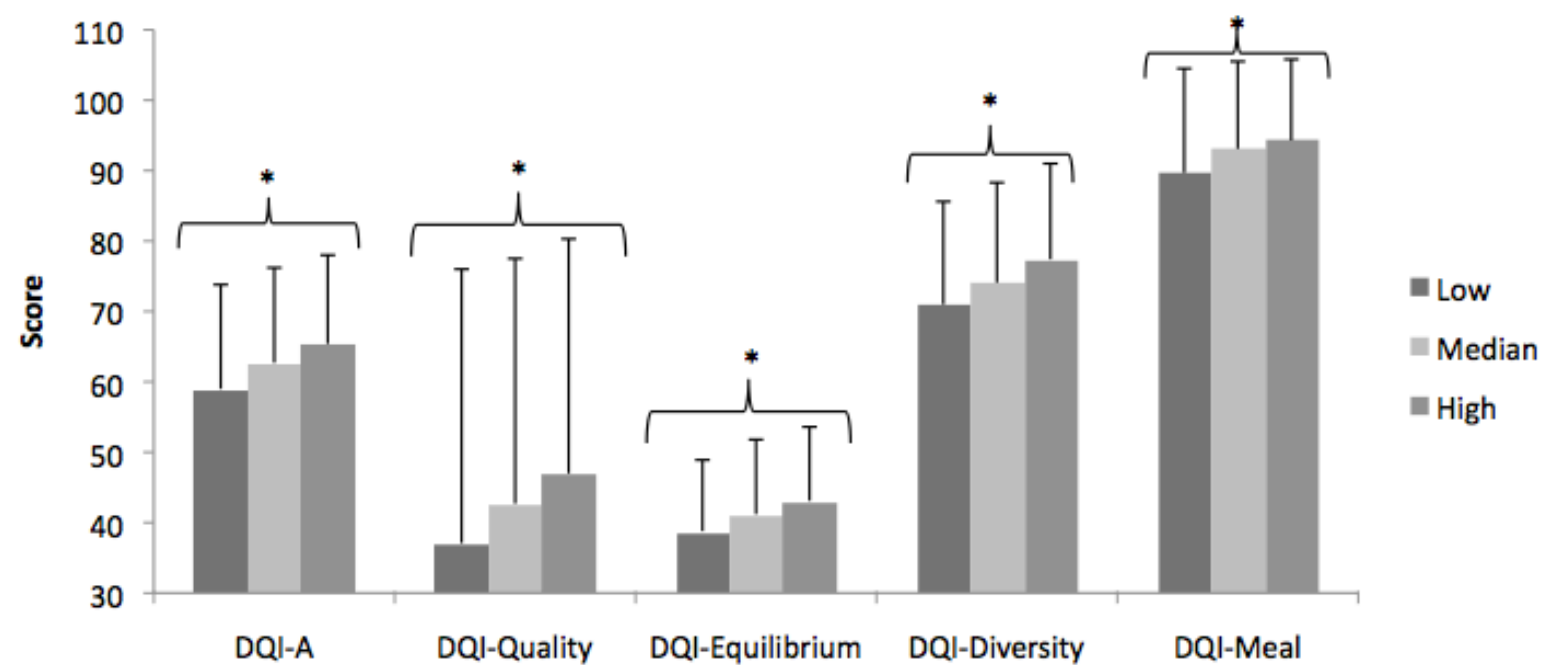

Figure 1. DQI-A according to the adolescents' dietary quality awareness

'DQI-A: Diet Quality Index-Adolescents

* P for trend adjusted for center using linear mixed effect model (diet perception level was treated as an ordinal factor $)(\mathrm{p}<0.0001)$

Values are mean (Standard Deviation) 